\title{
BMJ Open Are familial factors underlying the association between socioeconomic position and prescription medicine? A register-based study on Danish twins
}

\author{
Mia Madsen, ${ }^{1,2}$ Per Kragh Andersen, ${ }^{3}$ Mette Gerster, ${ }^{4}$ Anne-Marie Nybo Andersen, ${ }^{5}$ \\ Merete Osler, ${ }^{2,6}$ Kaare Christensen ${ }^{1}$
}

To cite: Madsen $\mathrm{M}$,

Andersen PK, Gerster M, et al. Are familial factors underlying the association between socioeconomic position and prescription medicine? A register-based study on Danish twins. BMJ Open 2013:3:e003292.

doi:10.1136/bmjopen-2013003292

- Prepublication history and additional material for this paper is available online. To view these files please visit the journal online (http://dx.doi.org/10.1136/ bmjopen-2013-003292).

Received 23 May 2013 Revised 1 September 2013 Accepted 9 October 2013

CrossMark

For numbered affiliations see end of article.

Correspondence to

Mia Madsen;

mimadsen@health.sdu.dk

\section{ABSTRACT}

Objectives: Although well established, the association between socioeconomic position and health and health behaviour is not clearly understood, and it has been speculated that familial factors, for example, dispositional factors or exposures in the rearing environment, may be underlying the association. The objective was to compare prescription fillings within twin pairs who are partly or fully genetically identical and share childhood exposures.

Design: Twin cohort study.

Setting: Denmark.

Participants: Data from the Danish Twin Registry were linked to registers in Statistics Denmark and the Danish Registry of Medicinal Product statistics. A total of 8582 monozygotic (MZ) and 15788 dizygotic same sex (DZSS) twins were included.

Outcome measures: Number of prescription fillings during follow-up (1995-2005) was analysed according to education and income. Results of unpaired and intrapair analyses were compared.

Results: An inverse social gradient in filling of prescriptions for all-purpose and system-specific drugs was observed in the unpaired analyses. In the intrapair analyses, associations were attenuated some in DZSS and more in MZ twins. Filling of drugs targeting the nervous system was still strongly associated with income in the intrapair analyses.

Conclusions: Familial factors seem to account for part of the observed social inequality in filling of prescription medicine.

\section{INTRODUCTION}

Social inequalities in health and health behaviour have been widely demonstrated in many societies, including the Scandinavian countries. ${ }^{1}$ Often social disparities in health are not confined to the most marginalised groups of society but are expressed as a gradient over the entire spectrum of social stratification. ${ }^{2}$ The inverse relationship between socioeconomic position (SEP) and health has consistently been observed across different social

\section{Strengths and limitations of this study}

- This study is based on nation-wide register data covering more than a decade, and we present results from a largely unselected population of more than 8000 monozygotic and 15000 dizygotic same sex twins.

- This is the first twin study on health inequalities to report such clear-cut findings with sufficient power for meaningful interpretation of intrapair analyses and for comparison of zygosity-specific results.

- Prescription fillings are not a perfect measure of health status, but we still argue that it is an inventive and fairly valid indicator in a Danish setting where prescription medicine has to be prescribed by a medical doctor and accounts for $90 \%$ of the total drug sale.

- The twin study is clearly a powerful approach, but when interpreting findings, alternative explanations for the pattern of attenuation should be considered, including measurement error and unshared confounding. However, in this case we find it unlikely that these potential sources of bias could fully explain our findings.

indicators and for numerous types of health outcomes. ${ }^{3}{ }^{4}$ Use of prescription medicine is one health-related outcome that has been found to be socially patterned, where Danish data have shown a greater use among people with low SEP compared with people with high SEP. ${ }^{5}{ }^{6}$ Denmark has a tax-financed decentralised healthcare system with a partly needdependent reimbursement system for outpatient prescription drugs. All prescription drugs have to be prescribed by a medical doctor and, compared with a number of other countries, prescription medicine constitute the majority of the total drug sales in Denmark (approximately 90\%). ${ }^{7}$ Many studies have shown substantially reduced social differences in drug use when health status have 
been taken into account, ${ }^{6} 89$ which may indicate that filling of prescription medicine to a large extent reflects health status. This is supported by the fact that comorbidity indices, based on prescription drug dispensings, have been established as strong predictors of mortality, ${ }^{10}$ and that drug use has proven to be a valid indicator of selfrated health. ${ }^{11}{ }^{12}$ However, other factors such as healthcare seeking behaviour and access to healthcare ${ }^{13} 14$ may also influence drug use, but the social gradient in these factors would, theoretically, be expected to be opposite that of health status, that is, greater drug use among people with high SEP compared with low SEP. Such a positive association is generally not supported by the existing Danish literature. ${ }^{5615}$

Although well established, the inverse association between SEP and health and health behaviour is not clearly understood, but many factors during the life course may play a role in the production of these social health differences. Suggested pathways include: material deprivation, behavioural factors and psychological factors. ${ }^{16}$ It has also been suggested that it is not SEP in adulthood per se that influences health, but underlying familial factors already at play in early life, ${ }^{17}{ }^{18}$ for example, rearing environment or genetic make-up are associated both with the obtainment of adult SEP and health status later in life.

In a recent commentary, Gilman and Loucks ${ }^{19}$ discuss why childhood environment may be such an important underlying factor in the production of social health differences. They argue that because childhood encompasses developmentally sensitive periods for the acquisition of cognitive, psychological and social skills that have a profound impact on an individual's capacity for long-term health and provide opportunities (and constraints) for adult socioeconomic conditions, it can potentially influence the association between any adult risk factor and later life health. ${ }^{19}$ The potential role of genetic setup in explaining health inequalities is reviewed by Mackenbach, ${ }^{20}$ who suggests that the most plausible set of hypotheses relates to genetic influences of personal attributes such as cognitive ability, personality and bodily and mental fitness that may influence both SEP and adult health status.

With the discordant twin pair design, it is possible to investigate the effect of adult SEP on prescription fillings eliminating confounding from factors shared by a pair of twins, exploiting that twins are partly or fully genetically identical and have experienced a similar childhood environment due to their common upbringing. This approach has been applied in a number of previous twin studies investigating different health outcomes, including mortality, ${ }^{21}$ hospitalisations, ${ }^{22}$ breast cancer ${ }^{23}$ and also softer endpoints such as depression scores and self-rated health. ${ }^{24}{ }^{25}$ However, the majority of these studies suffer from power limitations either due to small sample sizes and/or rare outcomes, making interpretations difficult.

In this study we aimed to investigate if there was an effect of SEP in adulthood on the number of prescription fillings above and beyond the effect of shared familial factors. Filling of prescription medicine is a quantitative health measure rendering sufficient power for the intrapair comparisons. Differences in genetic relatedness between monozygotic (MZ; genetically identical) and dizygotic (DZ) twins (share on average $50 \%$ of segregating genes) may further give an indication of the possible types of confounding (ie, genetic or environmental factors). In the theoretical situation of no measurement error and no confounding from unshared factors, genetic confounding would be indicated if an observed social gradient in prescription medicine was partly attenuated in DZ twins and fully attenuated in MZ twins, when shared familial factors had been taken into account. Likewise, an attenuation of similar size in DZ and MZ twins would be compatible with shared environmental confounding. Finally, to support a SEP effect on prescription fillings not due to confounding from shared familial factors, the association would have to persist in both DZ and MZ twins.

To support the utility of prescription medicine as a health indicator we also analysed its association with mortality.

\section{METHODS}

\section{Study population}

Data from the Danish Twin Registry were linked with information in the Danish Registry of Medicinal Products and administrative registers in Statistics Denmark. The study population consisted of 24370 twins, including $8582 \mathrm{MZ}$ and 15788 dizygotic same sex (DZSS) twins, who were born during 1921-1965 and alive and resident in Denmark at the beginning of follow-up (1 January 1995), after exclusions due to triplets $(\mathrm{n}=384)$ unknown zygosity (UZ; $\mathrm{n}=3731)$, and dizygotic opposite sex pairs $(n=16710)$, missing data on education or income $(n=845)$ and non-intact twin pairs in which one twin was dead, emigrated or had missing information $(n=2847)$. To evaluate the representativeness of the results from the unpaired twin analyses, we also analysed a 5\% population-based sample of the Danish population $(\mathrm{n}=137300)$.

\section{Social indicators}

We used information on the highest attained education in 1995 at age of $30+$ of the study population, categorised according to the International Standard Classification of Education of $1997^{26}$ into: primary/ lower secondary education (basic compulsory education), upper secondary education (secondary) and tertiary education (Bachelor's degree and above). Income was measured as an average of the equivalised gross household income (Danish currency) in 1994-1995, grouped into quartiles within each birth cohort. 'Equivalised' income is adjusted to take into account that households can share resources. Inspired by the standard Organisation for Economic Co-operation and 
Development equivalence scale $^{27}$ the householddenominator was constructed according to an equivalence scale that assigned a value of 1 to the first household member, of 0.7 to the second household member and of 0.5 to each additional household member. Calculating quartiles by birth cohort is aiming at taking into account that income is not fully comparable at different ages during the life course. An implication of this is that the income measure reflects a relative rather than absolute income level.

\section{Prescription medicine}

The Danish Registry of Medicinal Products was established in 1995 and contains information on the total sale of prescription medicine in Denmark registered by the pharmacies via a computerised accounting system. The drug information is recorded according to the Anatomical Therapeutic Chemical classification system $(\text { ATC })^{28}$ where the active substances in drugs are divided into different groups, primarily according to the organ system on which they act. Other information includes date of dispensing and daily defined doses (DDD), defined as the assumed average maintenance dose per day for a drug used for its main indication in adults. ${ }^{28}$ Outcomes of interest were defined as the number of prescription fillings during follow-up for all-purpose medication (ACT-groups: A, B, C, D, G, H, J, L, M, N, P, Q, R, S, V, excluding $Q$ which is for veterinary use, and G02B and G03A, which are for contraceptive use) and four groups of system-specific medication: ATC-C (heart/circulatory system), ATC-N (nervous system), ATC-R (respiratory system) and ATC-A (alimentary tract/metabolism). If no ATC code was assigned a prescription, it was excluded (1\%). DDD was used as a supplementary outcome measure.

\section{Other covariates}

Sex and age were included in the analyses. Analyses were performed separately for MZ and DZSS twins. Zygosity had previously been determined by questionnaire, ${ }^{29}$ a method that has proven valid with an overall misclassification frequency of less than $5 \%$ validated against a classification based on genetic markers. ${ }^{30}$

\section{Data analysis}

Analyses were carried out using Cox regression for recurrent events (proportional means regression), thereby accommodating multiple events (prescription fillings) per individual. ${ }^{31}$ Age was used as underlying timevariable and participants were followed from age at baseline to the age at the end of follow-up (31 December 2005 ) or death or emigration, and the timing of each prescription filling during this period was recorded. Both unpaired and intrapair analyses were performed. In the unpaired analyses robust SEs were used to account for the interdependence of observations within pairs and within each individual. Results of the unpaired analyses were compared with the intrapair analyses, which were performed using a stratified Cox model: $\mathrm{EN}_{\mathrm{ij}}(\mathrm{t})=\mu_{0 \mathrm{j}}(\mathrm{t}) \mathrm{e}^{\beta^{\prime} \mathrm{z}_{\mathrm{ij}}}$. Here $\mathrm{EN}_{\mathrm{ij}}(\mathrm{t})$ denotes the mean number of prescription fillings at time $t$ for an individual $\mathrm{i}$ belonging to twin pair $j, \mu_{0 \mathrm{j}}(\mathrm{t})$ the pair-specific baseline mean, and $\mathrm{e}^{\beta}$ the effect of the covariates adjusted for shared familial factors. Thus, in this analysis the mean number of prescription fillings was compared within twin pairs, thereby controlling for familial factors shared by a pair of twins. In the stratified model only SEP-discordant twin pairs contribute information to the $\beta$-parameter for SEP, although concordant pairs may contribute information to other $\beta$-parameters.

As counting process models do not allow simultaneous events, only one prescription of interest per day was included in the analysis.

Analyses were performed separately for zygosity and sex, and potential interactions between the social indicators and zygosity, sex and age, respectively, were evaluated by including interaction terms in the models and using Wald test statistics. To analyse the association between prescriptions and mortality, we used a Cox regression model, continuously updating the number of prescription fillings over time. Descriptive intrapair correlations were calculated as polychoric correlation coefficients.

\section{Subanalyses}

Since DDD may reflect the actual drug use more precisely than the number of prescription fillings, mean DDD were also analysed by means of a fixed-effects linear regression model taking censoring into account. ${ }^{32}$ This was treated as a subanalysis due to the highly rightskewed distribution of DDD, making linear regression a less optimal choice of model.

Permission for linkage and use of data for this study was obtained from the Danish Data Protection Board (2000-54-0047).

\section{RESULTS}

According to table 1 , showing the distribution of education and income in the population, men were better educated than women. Generally, the education of the twin population was comparable to that of the population-based sample. Only UZ twins had a markedly lower educational status and a higher proportion of missing information. The table also shows the mean income within each quartile. Twins have a somewhat higher mean income as compared to the populationbased sample.

The proportion of education-discordant twin pairs was $30 \%$ for MZ twins and $42 \%$ for DZSS twins, while $61 \%$ MZ twins and $68 \%$ DZSS twins were discordant on income (table 2).

In the twin population, $1.9 \%$ did not redeem any drug prescriptions during the total follow-up period and $25 \%$ redeemed less than one prescription/year, on average (results not shown). Overall, women filled more 
Table 1 Descriptives on educational status and income in a $5 \%$ population-based sample $(n=144749)$ and a population of Danish twins ( $n=48$ 887), including intact and non-intact twin pairs, stratified on sex and zygosity

\begin{tabular}{|c|c|c|c|c|c|c|c|c|c|c|c|c|c|c|c|c|}
\hline \multirow[b]{3}{*}{ Sex } & \multicolumn{4}{|c|}{$5 \%$ Population sample } & \multicolumn{4}{|c|}{ All twins } & \multirow{2}{*}{\multicolumn{2}{|c|}{$\frac{\text { DZSS }}{(n=18426)}$}} & \multirow{2}{*}{\multicolumn{2}{|c|}{$\begin{array}{l}M Z \\
(n=9636)\end{array}$}} & \multirow{2}{*}{\multicolumn{2}{|c|}{$\begin{array}{l}\text { DZOS } \\
(n=16710)\end{array}$}} & \multirow{2}{*}{\multicolumn{2}{|c|}{$\frac{U Z}{(n=3731)}$}} \\
\hline & \multirow[t]{2}{*}{$\overline{\mathbf{N}}$} & \multirow[t]{2}{*}{ Per cent ${ }^{\star}$} & \multirow[t]{2}{*}{ Mean } & \multirow[t]{2}{*}{ SD } & \multicolumn{2}{|c|}{$(n=48887)$} & \multirow[t]{2}{*}{ Mean } & \multirow[t]{2}{*}{ SD } & & & & & & & & \\
\hline & & & & & $\overline{\mathbf{N}}$ & Per cent * & & & $\overline{\mathbf{N}}$ & Per cent * & $\overline{\mathbf{N}}$ & Per cent ${ }^{*}$ & $\overline{\mathbf{N}}$ & Per cent * & $\overline{\mathbf{N}}$ & Per cent * \\
\hline \multicolumn{17}{|c|}{ Educational status $†$} \\
\hline \multicolumn{17}{|c|}{ Men } \\
\hline Primary & 23550 & 32 & & & 8909 & 35 & & & 3553 & 36 & 1517 & 31 & 2882 & 34 & 957 & 43 \\
\hline Secondary & 31336 & 43 & & & 11237 & 44 & & & 4309 & 44 & 2292 & 47 & 3834 & 45 & 802 & 36 \\
\hline Tertiary & 13722 & 19 & & & 4515 & 18 & & & 1685 & 17 & 963 & 20 & 1530 & 18 & 337 & 15 \\
\hline Missing & 4072 & 6 & & & 800 & 3 & & & 310 & 3 & 128 & 3 & 208 & 2 & 154 & 7 \\
\hline Total & 72680 & 100 & & & 25461 & 100 & & & 9857 & 100 & 4900 & 101 & 8454 & 99 & 2250 & 101 \\
\hline \multicolumn{17}{|l|}{ Women } \\
\hline Primary & 31215 & 43 & & & 10182 & 44 & & & 3857 & 45 & 1903 & 40 & 3633 & 44 & 789 & 53 \\
\hline Secondary & 23809 & 33 & & & 7805 & 34 & & & 2868 & 34 & 1730 & 37 & 2807 & 34 & 400 & 27 \\
\hline Tertiary & 14229 & 20 & & & 4613 & 20 & & & 1696 & 20 & 1004 & 21 & 1705 & 21 & 208 & 14 \\
\hline Missing & 2816 & 4 & & & 442 & 2 & & & 148 & 2 & 99 & 2 & 111 & 1 & 84 & 6 \\
\hline Total & 72069 & 100 & & & 23042 & 100 & & & 8569 & 101 & 4736 & 100 & 8256 & 100 & 1481 & 100 \\
\hline \multicolumn{17}{|c|}{ Income $\neq$ (DKK) } \\
\hline \multicolumn{17}{|l|}{ Men } \\
\hline 1st quartile & 17348 & 24 & 88537 & 28373 & 5931 & 24 & 92330 & 27563 & 2251 & 23 & 1061 & 22 & 1929 & 23 & 690 & 31 \\
\hline 2nd quartile & 17510 & 24 & 145676 & 25887 & 6523 & 24 & 149367 & 24179 & 2563 & 26 & 1208 & 25 & 2201 & 26 & 551 & 24 \\
\hline 3rd quartile & 17976 & 25 & 191360 & 34863 & 6769 & 25 & 196738 & 31365 & 2612 & 27 & 1375 & 28 & 2246 & 27 & 536 & 24 \\
\hline 4th quartile & 18228 & 25 & 311232 & 141784 & 5960 & 25 & 314180 & 225459 & 2340 & 24 & 1218 & 25 & 2006 & 24 & 396 & 18 \\
\hline Missing & 1618 & 2 & & & 278 & 2 & & & 91 & 1 & 38 & 1 & 72 & 1 & 77 & 3 \\
\hline Total & 72680 & 100 & & & 25461 & 100 & & & 9875 & 101 & 4900 & 101 & 8454 & 101 & 2250 & 100 \\
\hline Women & & & & & & & & & 2174 & 25 & 1158 & 24 & 2200 & 27 & 538 & 36 \\
\hline 1st quartile & 18958 & 26 & 88201 & 26316 & 6070 & 26 & 91205 & 25698 & 2316 & 27 & 1222 & 26 & 2186 & 27 & 353 & 24 \\
\hline 2nd quartile & 18219 & 25 & 142746 & 27689 & 6077 & 25 & 146427 & 25562 & 2152 & 25 & 1224 & 26 & 2106 & 26 & 313 & 21 \\
\hline 3rd quartile & 17753 & 25 & 18942 & 36067 & 5795 & 25 & 194968 & 33291 & 1882 & 22 & 1097 & 23 & 1730 & 21 & 232 & 16 \\
\hline 4th quartile & 16126 & 22 & 308876 & 225888 & 4941 & 22 & 312063 & 173113 & 45 & 1 & 35 & 1 & 34 & 0 & 45 & 3 \\
\hline Missing & 1013 & 1 & & & 159 & 1 & & & 8569 & 100 & 4736 & 100 & 8256 & 101 & 1481 & 100 \\
\hline Total & 72069 & 99 & & & 23042 & 99 & & & 2251 & 23 & 1061 & 22 & 1929 & 23 & 690 & 31 \\
\hline
\end{tabular}

\section{*May not sum to 100 because of rounding.}

International Standard Classification of Education.

$\ddagger$ Average of equivalised gross household income in 1994-1995 in quartiles.

DKK, Danish crowns; DZOS, dizygotic opposite sex twins; DZSS, dizygotic same sex twins; MZ, monozygotic twins; UZ, unknown zygosity 
Table 2 Descriptives on intrapair discordances on educational status and income, stratified on zygosity in a population of Danish twins $(n=24370)$

\begin{tabular}{|c|c|c|c|c|}
\hline & \multicolumn{2}{|l|}{ DZSS } & \multicolumn{2}{|l|}{ MZ } \\
\hline & \multicolumn{2}{|c|}{$(n=15788)$} & \multicolumn{2}{|c|}{$(n=8582)$} \\
\hline & $\overline{\mathbf{N}}$ & Per cent ${ }^{\star}$ & $\overline{\mathbf{N}}$ & Per cent $^{\star}$ \\
\hline \multicolumn{5}{|l|}{ Educational status } \\
\hline Primary vs secondary & 3590 & 23 & 1460 & 17 \\
\hline Primary vs tertiary & 900 & 6 & 316 & 4 \\
\hline Secondary vs tertiary & 2194 & 14 & 820 & 10 \\
\hline Any discordance & 6684 & 42 & 2596 & 30 \\
\hline \multicolumn{5}{|l|}{ Income } \\
\hline 1st quartile vs 2nd quartile & 2048 & 13 & 1072 & 12 \\
\hline 1st quartile vs 3rd quartile & 1706 & 11 & 754 & 9 \\
\hline 1st quartile vs 4 th quartile & 1158 & 7 & 490 & 6 \\
\hline 2nd quartile vs 3rd quartile & 2266 & 14 & 1194 & 14 \\
\hline 2nd quartile vs 4th quartile & 1574 & 10 & 682 & 8 \\
\hline 3rd quartile vs 4th quartile & 2000 & 13 & 1080 & 13 \\
\hline Any discordance & 10752 & 68 & 5272 & 61 \\
\hline
\end{tabular}

prescriptions than men for all age groups and the number of prescription fillings increased with age in both sexes (table 3).

ATC-N drug prescriptions were the most frequently redeemed in the youngest age group. The mean number of prescription fillings in the twin population was similar to that in the population-based sample, although slightly higher in the population-based sample.

In order to get a better idea of the clinical outcomes underlying the observed prescription patterns, we have included a more detailed description of the most incident types of drugs at the 3-digit and 4-digit ATC level (see online supplementary table S1). From the table it appears that the ATC-C category primarily comprises drugs indicated for hypertension and ischaemic heart disease, while the ATC-N category includes drugs indicated for a wide range of different diagnoses, including chronic pain disorders, insomnia, anxiety, psychoses, depression, etc. ${ }^{28}$ In the ATC-R category the main types of drugs are drugs for obstructive airway disease such as asthma and chronic obstructive lung disorder (COPD). ${ }^{28}$ Finally, drugs for acid-related disorders and diabetes are the main constituents of the ATC-A category. The results of an analysis of the association between SEP and prescription fillings for all-purpose and system-specific drugs are presented in table 4 .

For all-purpose drugs, MZ twins in the highest income quartile had a $30 \%$ lower mean number of prescription fillings than $\mathrm{MZ}$ twins in the lowest income quartile $(\mathrm{MR}=0.70$ (95\% CI 0.65 to 0.77$))$. Similarly, MZ twins with a tertiary education had $17 \%$ lower mean number of prescription fillings than twins with a primary education $(\mathrm{MR}=0.82(95 \% \mathrm{CI} 0.75$ to 0.89$))$. The association was slightly less strong for ATC-C drugs while stronger associations could be observed for the other systemspecific drugs, particularly for ATC-N. In the unpaired analyses, no large differences could be observed between MZ and DZSS twins and there was no strong evidence for an interaction between SEP and zygosity in the unpaired analysis (education $\mathrm{p}=0.81$, income $\mathrm{p}=0.95)$. In contrast, the effect of SEP was moderated by zygosity in the intrapair analyses (education $\mathrm{p}=0.02$, income $\mathrm{p}=0.05$ ), suggesting a more attenuated effect of SEP in MZ twins than in DZSS twins. In MZ twins, generally no statistically significant effect of education could be observed, while income was still somewhat associated with all-purpose medication and quite strongly with ACT-N drugs. In DZSS twins, a minor or moderate attenuation could be observed, and all effect parameters were statistically significant, except for ATC-C drugs. In the population-based sample, the associations were similar to that in the overall twin population.

When using DDD (for all-purpose drugs) as outcome measure (table 5), results similar to the results based on the number of prescription fillings were obtained, although the attenuation patterns in MZ twins were somewhat more clear in this analysis, showing no statistically significant associations with DDD of neither education nor income. In the analysis of number of prescriptions as a predictor of mortality, we found a $60 \%$ increase in mortality rate during follow-up for a person who, on average, filled one prescription per month during the follow-up period compared with a person without any prescription fillings $(\mathrm{HR}=1.60$ (95\% CI 1.25 to 2.05$))$.

\section{DISCUSSION}

\section{Summary of findings}

In this large Danish twin population we demonstrated an inverse social gradient in fillings of prescription medicine for all-purpose and system-specific drugs. That 
Table 3 Mean number of prescription fillings after 1 and 10 years of follow-up in a $5 \%$ population-based sample and a population of Danish twins, stratified on age and sex

\begin{tabular}{lll}
\hline Type of drugs & \multicolumn{2}{l}{ Nelson-Aalen cumulative hazard } \\
\cline { 2 - 3 } Age & $\begin{array}{l}5 \% \text { Population } \\
(n=137300)\end{array}$ & Twins $(n=24370)$ \\
& 1 year 10 years & 1 year 10 years \\
\hline
\end{tabular}

All purpose

30-44 years

$\begin{array}{lrrrr}\text { Men } & 2.5 & 28.7 & 2.2 & 25.9 \\ \quad \text { Women } & 4.1 & 44.5 & 3.8 & 41.1 \\ \begin{array}{l}\text { 5-59 years } \\ \text { Men }\end{array} & 3.6 & 47.4 & 3.3 & 43.1 \\ \quad \text { Women } & 6.0 & 71.9 & 5.7 & 68.4 \\ \begin{array}{l}\text { (0+ years } \\ \text { Men }\end{array} & 6.4 & 87.5 & 5.8 & 82.2 \\ \quad \text { Women } & 8.3 & 105.4 & 7.2 & 95.7\end{array}$

Circulatory system (ATC-C)

30-44 years

$\begin{array}{lllll}\text { Men } & 0.1 & 3.3 & 0.1 & 2.9\end{array}$

$\begin{array}{lllll}\text { Women } & 0.2 & 4.2 & 0.2 & 3.6\end{array}$

45-59 years

Men

0.7

12.6

0.6

10.6

Women

0.8

13.8

0.7

13.0

$60+$ years

Men

1.9

29.6

1.7

Women

1.9

30.0

1.6

27.4

Nervous system (ATC-N)

30-44 years

$\begin{array}{lrrrr}\text { Men } & 0.8 & 9.8 & 0.7 & 8.6 \\ \text { Women } & 1.1 & 14.5 & 1.0 & 13.3 \\ \text { 5-59 years } & & & & \\ \text { Men } & 1.2 & 14.6 & 1.2 & 13.9\end{array}$

$\begin{array}{lllll}\text { Women } & 2.1 & 25.0 & 2.0 & 24.1\end{array}$

$60+$ years

Men

$1.8 \quad 24.4$

1.6

22.2

Women

3.1

39.2

2.7

35.8

Respiratory system (ATC-R)

30-44 years

$\begin{array}{lllll}\text { Men } & 0.3 & 3.9 & 0.3 & 3.6\end{array}$

Women

0.6

6.5

0.5

45-59 years

$\begin{array}{lllll}\text { Men } & 0.5 & 5.8 & 0.4 & 5.0\end{array}$

Women

0.8

9.8

0.7

9.1

$60+$ years

$\begin{array}{lllll}\text { Men } & 1.1 & 14.4 & 0.9 & 12.5\end{array}$

$\begin{array}{lllll}\text { Women } & 1.2 & 14.8 & 1.0 & 12.8\end{array}$

Alimentary tract and metabolism (ATC-A)

30-44 years

$\begin{array}{lllll}\text { Men } & 0.3 & 3.5 & 0.2 & 3.1\end{array}$

$\begin{array}{lllll}\text { Women } & 0.4 & 5.0 & 0.4 & 4.1\end{array}$

45-59 years

Men

Women

0.5

0.7

7.6

0.5

6.6

$60+$ years

$\begin{array}{lllll}\text { Men } & 1.1 & 15.4 & 1.1 & 15.0\end{array}$

$\begin{array}{lrrrr}\text { Women } & 1.3 & 18.3 & 1.0 & 16.4\end{array}$

ATC, Anatomical Therapeutic Chemical classification system. is, a greater use of prescription medicine among those with a low SEP thus suggesting a worse health status of this group. Furthermore, the number of prescription fillings was shown to be associated with a greater risk of mortality. In the intrapair analyses, where shared familial factors were controlled per design, the association between SEP and prescription fillings attenuated to a wide extent within MZ twins and statistically significantly less in DZSS twins. For education, there was generally no association with prescription fillings in the intrapair analyses of MZ twins, except for drugs targeting the nervous system, while there was still some association of income with all-purpose medication and most system-specific drugs. However, no effect of income was seen in the intrapair analyses when DDD were used as outcome measure. In spite of some variations between systemspecific drugs, the overall pattern was the same as for allpurpose drugs, except for ATC-N drugs and to a lesser degree ATC-A drugs, which still showed some effect of SEP in the intrapair analyses.

\section{Interpretation}

The fact that the association was attenuated in the intrapair analyses suggests that underlying factors shared by a pair of twins account for some of the observed association between SEP and prescription fillings. However, there may be a number of alternative or complementary explanations for this finding: first, part of it is likely caused by measurement error. Measurement error is random and therefore not shared by twins. In the intrapair analysis, variance due to shared factors is removed, and a relatively larger proportion of exposure variance is thus due to measurement error. This will result in increasing attenuation of parameter estimates in the intrapair analyses. ${ }^{33}$ However, since data come from official registers it can be expected that education and income have limited measurement error. Second, the behaviour of one twin could be affected by the behaviour of the other twin, that is, 'social interaction' either by 'imitation' or 'differentiation'. The implications of a potential imitation could be smaller within-pair differences, which could be misinterpreted as confounding from underlying familial factors. This may be of some concern in this study since fillings of prescription medicine is likely to have a behavioural component. Another implication of the discordant twin pair approach is that only twin pairs who are discordant on exposure contribute with statistical information to the estimation of SEP effects in the intrapair analysis. This could potentially induce bias in the comparison of the unpaired and intrapair analysis, since the two analyses are based on only partly overlapping populations. Since MZ twins are less likely to be discordant, the selection bias may be most severe in MZ twins. ${ }^{34}$ We examined this concern by restricting the unpaired analysis only to include groups with exposure-discordant twins. Results were similar to 
Table 4 Ratio (MR) of the mean number of prescription fillings (1995-2005) for all-purpose and system-specific drugs according to educational status and income in a 5\% population-based sample (137 300) and a population of Danish twins $(n=24370)$, showing results from unpaired and intrapair analyses stratified on zygosity

\begin{tabular}{|c|c|c|c|c|c|c|c|c|c|c|}
\hline \multirow[b]{3}{*}{ Type of drug } & \multicolumn{6}{|c|}{ Unpaired analysis* } & \multicolumn{4}{|c|}{ Intrapair analysis $†$} \\
\hline & \multicolumn{2}{|c|}{$\begin{array}{l}\% \text { Population } \\
n=137300\end{array}$} & \multicolumn{2}{|c|}{$\begin{array}{l}\text { Twins } \\
\text { DZSS } n=15788\end{array}$} & \multicolumn{2}{|c|}{$M Z n=8582$} & \multicolumn{2}{|c|}{ DZSS } & \multicolumn{2}{|l|}{ MZ } \\
\hline & $\overline{\mathrm{MR}}$ & $95 \% \mathrm{Cl}$ & $\overline{\mathrm{MR}}$ & $95 \% \mathrm{Cl}$ & $\overline{\mathrm{MR}}$ & $95 \% \mathrm{Cl}$ & $\overline{\mathrm{MR}}$ & $95 \% \mathrm{Cl}$ & $\overline{\mathrm{MR}}$ & $95 \% \mathrm{Cl}$ \\
\hline \multicolumn{11}{|l|}{ All purpose } \\
\hline \multicolumn{11}{|l|}{ Education } \\
\hline Secondary & 0.90 & 0.90 to 0.90 & 0.90 & 0.86 to 0.95 & 0.87 & 0.81 to 0.93 & 0.88 & 0.84 to 0.93 & 0.97 & 0.91 to 1.03 \\
\hline Tertiary & 0.82 & 0.82 to 0.83 & 0.85 & 0.80 to 0.91 & 0.83 & 0.76 to 0.90 & 0.86 & 0.80 to 0.92 & 0.95 & 0.86 to 1.05 \\
\hline \multicolumn{11}{|l|}{ Income } \\
\hline 2nd quartile & 0.78 & 0.78 to 0.78 & 0.81 & 0.76 to 0.85 & 0.81 & 0.75 to 0.88 & 0.86 & 0.82 to 0.91 & 0.91 & 0.85 to 0.97 \\
\hline 3rd quartile & 0.72 & 0.72 to 0.73 & 0.72 & 0.69 to 0.77 & 0.74 & 0.69 to 0.80 & 0.79 & 0.75 to 0.83 & 0.87 & 0.81 to 0.94 \\
\hline 4th quartile & 0.70 & 0.70 to 0.70 & 0.71 & 0.67 to 0.75 & 0.70 & 0.65 to 0.77 & 0.76 & 0.72 to 0.81 & 0.87 & 0.81 to 0.94 \\
\hline \multicolumn{11}{|c|}{ Circulatory system (ATC-C) } \\
\hline \multicolumn{11}{|l|}{ Education } \\
\hline Secondary & 0.95 & 0.95 to 0.96 & 0.92 & 0.85 to 0.99 & 0.87 & 0.78 to 0.96 & 0.85 & 0.79 to 0.92 & 0.89 & 0.81 to 0.97 \\
\hline Tertiary & 0.79 & 0.79 to 0.80 & 0.78 & 0.71 to 0.87 & 0.70 & 0.60 to 0.82 & 0.80 & 0.71 to 0.90 & 0.93 & 0.79 to 1.08 \\
\hline \multicolumn{11}{|c|}{ 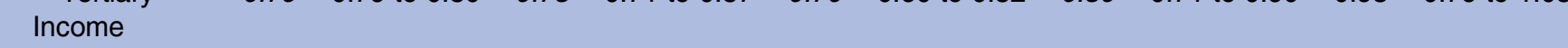 } \\
\hline 2nd quartile & 0.91 & 0.90 to 0.91 & 0.94 & 0.87 to 1.03 & 0.94 & 0.84 to 1.06 & 1.08 & 0.99 to 1.17 & 0.95 & 0.87 to 1.05 \\
\hline 3rd quartile & 0.83 & 0.83 to 0.84 & 0.86 & 0.78 to 0.94 & 0.86 & 0.76 to 0.97 & 0.97 & 0.89 to 1.06 & 0.98 & 0.89 to 1.08 \\
\hline 4th quartile & 0.79 & 0.79 to 0.79 & 0.82 & 0.74 to 0.90 & 0.85 & 0.74 to 0.97 & 0.97 & 0.88 to 1.08 & 0.94 & 0.84 to 1.05 \\
\hline \multicolumn{11}{|c|}{ Nervous system (ATC-N) } \\
\hline \multicolumn{11}{|l|}{ Education } \\
\hline Secondary & 0.80 & 0.80 to 0.80 & 0.87 & 0.79 to 0.96 & 0.77 & 0.67 to 0.88 & 0.85 & 0.77 to 0.94 & 1.00 & 0.86 to 1.17 \\
\hline Tertiary & 0.71 & 0.71 to 0.71 & 0.77 & 0.67 to 0.88 & 0.75 & 0.61 .0 .92 & 0.78 & 0.67 to 0.90 & 0.91 & 0.73 to 1.16 \\
\hline \multicolumn{11}{|c|}{ 年 } \\
\hline 2nd quartile & 0.61 & 0.60 to 0.61 & 0.61 & 0.55 to 0.68 & 0.60 & 0.52 to 0.70 & 0.68 & 0.61 to 0.75 & 0.75 & 0.67 to 0.87 \\
\hline 3rd quartile & 0.49 & 0.49 to 0.50 & 0.47 & 0.43 to 0.53 & 0.47 & 0.39 to 0.56 & 0.54 & 0.48 to 0.61 & 0.59 & 0.50 to 0.70 \\
\hline 4th quartile & 0.44 & 0.44 to 0.44 & 0.45 & 0.40 to 0.51 & 0.42 & 0.35 to 0.50 & 0.50 & 0.45 to 0.57 & 0.60 & 0.50 to 0.71 \\
\hline \multicolumn{11}{|c|}{ Respiratory system (ATC-R) } \\
\hline \multicolumn{11}{|l|}{ Education } \\
\hline Secondary & 0.86 & 0.85 to 0.86 & 0.77 & 0.67 to 0.87 & 0.82 & 0.69 to 0.98 & 0.83 & 0.72 to 0.94 & 1.00 & 0.84 to 1.21 \\
\hline Tertiary & 0.81 & 0.80 to 0.81 & 0.79 & 0.68 to 0.92 & 0.76 & 0.61 to 0.95 & 0.80 & 0.66 to 0.97 & 0.77 & 0.58 to 1.03 \\
\hline \multicolumn{11}{|c|}{ 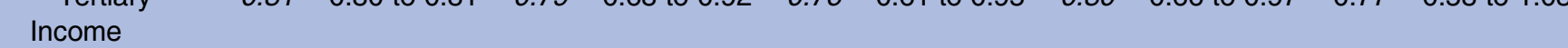 } \\
\hline 2nd quartile & 0.76 & 0.75 to 0.76 & 0.76 & 0.66 to 0.87 & 0.79 & 0.65 to 0.98 & 0.86 & 0.75 to 0.99 & 1.04 & 0.86 to 1.25 \\
\hline 3rd quartile & 0.68 & 0.68 to 0.69 & 0.74 & 0.64 to 0.86 & 0.69 & 0.57 to 0.85 & 0.85 & 0.73 to 0.98 & 1.02 & 0.84 to 1.24 \\
\hline 4th quartile & 0.63 & 0.63 to 0.63 & 0.69 & 0.59 to 0.81 & 0.64 & 0.52 to 0.79 & 0.83 & 0.71 to 0.96 & 1.25 & 1.04 to 1.51 \\
\hline \multicolumn{11}{|c|}{ Alimentary tract and metabolism (ATC-A) } \\
\hline \multicolumn{11}{|l|}{ Education } \\
\hline Secondary & 0.84 & 0.84 to 0.84 & 0.85 & 0.77 to 0.94 & 0.81 & 0.71 to 0.93 & 0.84 & 0.75 to 0.94 & 0.98 & 0.85 to 1.14 \\
\hline Tertiary & 0.68 & 0.67 to 0.68 & 0.72 & 0.62 to 0.83 & 0.64 & 0.53 to 0.77 & 0.81 & 0.68 to 0.96 & 0.94 & 0.76 to 1.17 \\
\hline Income & & & & & & & & & & \\
\hline 2nd quartile & 0.74 & 0.74 to 0.75 & 0.73 & 0.65 to 0.81 & 0.83 & 0.72 to 0.96 & 0.85 & 0.76 to 0.96 & 0.88 & 0.77 to 1.01 \\
\hline 3rd quartile & 0.64 & 0.64 to 0.65 & 0.63 & 0.56 to 0.71 & 0.77 & 0.66 to 0.90 & 0.77 & 0.68 to 0.87 & 0.87 & 0.75 to 1.02 \\
\hline 4th quartile & 0.61 & 0.61 to 0.61 & 0.60 & 0.53 to 0.68 & 0.65 & 0.55 to 0.77 & 0.76 & 0.67 to 0.88 & 0.86 & 0.72 to 1.02 \\
\hline $\begin{array}{l}\text { *Unpaired analysis } \\
\text { account. The interp } \\
\text { secondary or tertiar } \\
\text { education are mutu } \\
\text { tIntrapair analysis } \\
\text { secondary or tertiar } \\
\text { Italic typography in } \\
\text { ATC, Anatomical Th }\end{array}$ & te & istical sig & & evel. & ec $\mathrm{C}$ & on. & 2. & $\begin{array}{l}\text { example, } \\
\text { djusted for } \\
\text { a given tim }\end{array}$ & $\begin{array}{l}\text { with } \\
\text { vidi }\end{array}$ & $\begin{array}{l}\text { win pairs into } \\
\text { with a } \\
\text { Income and } \\
\text { ith a }\end{array}$ \\
\hline
\end{tabular}

those of the main analysis in both $\mathrm{MZ}$ and $\mathrm{DZ}$ twins. A further issue relates to the fact that twins who are discordant on exposure are special in the sense that they, in spite of overlapping genes and rearing environment, differ in their SEP. Thus, unshared factors may explain these differences. This implies that the intrapair analysis may still be confounded by unshared confounding factors, and that this confounding may be enforced in 
Table 5 Results from a linear regression model showing number of daily defined doses (DDD) for all-purpose drugs according to educational status and income in a population of Danish twins $(n=24370)$ stratified on zygosity

\begin{tabular}{|c|c|c|c|c|c|c|c|c|}
\hline \multirow{3}{*}{$\begin{array}{l}\text { Educational status } \\
\text { Income }\end{array}$} & \multicolumn{4}{|c|}{ Unpaired analysis* } & \multicolumn{4}{|c|}{ Intrapair analysis† } \\
\hline & \multicolumn{2}{|c|}{ DZSS n=15 788} & \multicolumn{2}{|c|}{$M Z n=8582$} & \multicolumn{2}{|l|}{ DZSS } & \multicolumn{2}{|l|}{ MZ } \\
\hline & $\overline{\text { DDD }}$ & $95 \% \mathrm{Cl}$ & DDD & $95 \% \mathrm{Cl}$ & $\overline{\text { DDD }}$ & $95 \% \mathrm{Cl}$ & DDD & $95 \% \mathrm{Cl}$ \\
\hline Secondary & -287 & -397 to -177 & -289 & -440 to -138 & -245 & -399 to -90 & -143 & -346 to 59 \\
\hline Tertiary & -404 & -531 to -277 & -424 & -606 to -243 & -344 & -557 to -131 & -152 & -440 to 136 \\
\hline 2nd quartile & -401 & -541 to -260 & -275 & -463 to -88 & -219 & -383 to -54 & 18 & -177 to 214 \\
\hline 3rd quartile & -541 & -680 to -402 & -451 & -638 to -263 & -367 & -535 to -198 & -83 & -287 to 121 \\
\hline 4th quartile & -505 & -648 to -363 & -437 & -630 to -243 & -327 & -512 to -142 & 16 & -209 to 242 \\
\hline
\end{tabular}

Results from unpaired and intrapair analyses are shown.

*Unpaired analysis treating twins as individuals while taking interdependence of observations within each individual and within twin pairs into account. The interpretation of, for example, the education estimate is difference in the mean number of DDDs of an individual with a secondary or tertiary education compared with a random individual with a primary education. The estimates are adjusted for age and sex. Income and education are mutually adjusted.

tIntrapair analysis of twins. The interpretation of for example, the education estimate is the difference in the mean number of DDDs of a twin with a secondary or tertiary education compared with its co-twin with a primary education.

Italic typography indicates statistical significance at $5 \%$ level.

DZSS, dizygotic same sex twins; MZ, monozygotic twins.

the intrapair analysis. ${ }^{33}$ Generally, confounding from unshared factors is thought to be more severe when confounders are less correlated than exposure. ${ }^{33}$ This may or may not be true in our case, since we can only hypothesise on the correlation of unmeasured confounders. Nevertheless, the correlation of education and income ( $\mathrm{MZ}=0.79, \mathrm{DZ}=0.58$ and $\mathrm{MZ}=0.49, \mathrm{DZ}=0.33)$ are more or less of the same magnitude as phenotypes like cognitive ability ${ }^{35}$ and body mass index ${ }^{36}$ that have previously been investigated using similar designs. In any case, as shown by Frisell $e t a l^{35}$ in order for increased confounding to explain the attenuation of the association observed in this study, the potential non-shared confounders would have to create a positive association between education and prescription fillings. In most cases, however, we would expect a negative association, although filling of prescription medicine is indeed a complex health outcome and it is theoretically possible for a confounder to have a dual effect on prescription fillings by (1) increasing the capability of getting the relevant prescriptions, for example, due to more regular heath checks or better understanding of symptoms (2) at the same time reducing the need for prescription fillings due to better health status. Nevertheless, in a Danish context health status does seem to be the main determinant of prescription medicine ${ }^{10} 3738$ and was clearly associated with mortality in this data. Thus, in the presence of non-shared confounding we would expect the net effect of any confounding to produce a negative association between education and prescription fillings resulting in a bias away from the null, ${ }^{33}$ and therefore it could not explain the observed attenuation of effect in the intrapair analyses observed in this study.

The finding of greatest attenuation in MZ twins is compatible with the scenario of genetic confounding described in the introduction. Since the genetic overlap is greater in MZ twins than DZSS twins, one would expect a larger attenuation in $\mathrm{MZ}$ twins, if genetic factors gave rise to the confounding. However, a number of other factors could produce a greater attenuation in MZ twins: first of all, the aforementioned measurement error may be most pronounced in MZ twins, due to the fact that increasing correlation in exposure will result in a greater attenuation of intrapair parameter estimates. ${ }^{33}$ In addition, the comparison of strength of association between MZ and DZ twins to indicate the source of familial confounding relies on the equal environment assumption: that is, MZ and DZ twins share their environment equally. However, this assumption may be challenged, and if it does not hold, that is, if MZ twins not only share their genes but also their environment more closely than DZ twins, ${ }^{39}$ shared environmental factors could also produce a greater attenuation of effect in MZ twins. However, the interplay between environment and genes is complex, and it is conceivable that the environment to a certain extent is shaped in response to the genetic dispositions of an individual. If, for instance, a genetically determined similar appearance of MZ twins also elicits a more similar treatment from their peers, then these similar environmental stimuli can also be ascribed to genetic factors. ${ }^{40}$

Thus, although several factors may contribute to the observed attenuation of association between SEP and filling of prescription drugs in the intrapair analyses and to the differences in strength of association between $\mathrm{MZ}$ and DZ twins, the findings suggest that a part of the observed social inequality in prescription fillings is explained by either genetic or environmental factors shared by twins.

The finding of a persistent association of particularly income with fillings of prescriptions for ATC-N drugs clearly stood out from the general results. We therefore carried out a post hoc subanalysis of specific categories of ATC-N drugs to test whether it were certain types of drugs driving the association. The analysis revealed that it was mainly for analgesics and psycholeptics that the 
association persisted, while the association was somewhat attenuated for psychoanaleptics (primarily antidepressants). This finding may support the notion of reverse causation, that is, that health status influences SEP rather than the other way around, since it is likely that diagnoses such as chronic pain disorders, psychoses, anxiety and bipolar disorders associated with these types of drugs may affect the work ability and thus the income of a person. Income is much more sensitive to reverse causation than education, which is usually obtained early in life and remains constant once it is obtained.

\section{Existing literature}

In this study we argue that fillings of all-purpose and system-specific drug prescriptions to some extent serve as an indicator of general health status and of conditions such as ischaemic heart disease, hypertension, COPD and diabetes. The finding of weaker effects of SEP, when underlying familial factors were taken into account, accords with a large part of the life-course literature that supports the importance of early life factors in the aetiology of chronic disease in adulthood. ${ }^{4142}$

In addition, a number of previous twin and sibling studies have investigated the association between various SEP indicators and health outcomes. While some studies have shown strong or some evidence of a causal effect of adult SEP ${ }^{43-47}$ other suggest no or little effect of SEP, when familial factors have been adjusted for. ${ }^{22} 48-51$ Other studies show mixed results. ${ }^{21}$ 23-25 $47 \quad 52-54$ However, the studies vary with respect to a number of important parameters hampering overall comparisons. Most importantly, investigated health outcomes differ and may have different aetiologies and show different social gradients and patterns of familial confounding, but even for specific-health outcomes there is no clear picture of evidence. For example, for mortality, two sibling ${ }^{45} 46$ and two twin studies ${ }^{21} 44$ have investigated the association with education. Although all studies support some effect of education after controlling for shared family factors, important differences exist: the twin study by Madsen $e t a l^{21}$ demonstrated an effect of education within twins only in older cohorts of men, but not in younger men and not in women. The influence of shared family factors was thus suggested in the latter, but not in the first subgroup of this study. The two sibling studies also suggested some effect of shared family factors, while the twin study by Lundborg ${ }^{43} \mathrm{did}$ not support any such effect. For self-rated health, the majority of the existing twin studies 2453 have shown mixed results, although Osler et $a t^{47}$ and Lundborg ${ }^{43} \mathrm{did}$ find a statistically significant association between social class respective education and self-rated health in the intrapair analyses. One important reason for the inconsistencies may be that many studies have suffered from power limitations in the intrapair analyses due to a small number of events. ${ }^{21} 23254753$ This is not a concern in this study, where almost all of the exposure discordant twins contributed with information to the intrapair analyses, thus providing some of the most powerful twin results on social inequality in health to date.

\section{Strengths and limitations}

The twin approach is clearly a strength of this study, since it makes it possible to adjust for unmeasured background factors shared by twins that may underlie the association between SEP and health. Furthermore, the large sample size and the long follow-up allow a great number of events to be analysed. In addition, the use of population-based registers has the advantage of relatively little selection and measurement error in the study population. Finally, this study not only focuses on prescription medicine in general, but also on drugs targeting specific organ systems which may give us a better idea of potential mechanisms.

Among study limitations is the fact that filling of prescription medicine is not a perfect measure of health status. We do, however, argue that the observed association with mortality and the inverse relationship with education and income likely reflect a greater need for medicine among people of lower SEP. In case that access to healthcare also plays a role, presumably favouring people of high SEP, the social gradient in health status in this study could be underestimated. Although data did not contain information on over-the-counter medication, it only constitutes a minor part of the total drug consumption in Denmark, ${ }^{7}$ and since we were interested in drugs as an indicator of health status, it could be argued that the most valid approach is to focus on drugs that require a formal medical indication (ie, prescription).

As models for counting processes only allow one event at a time, the number of prescription fillings was defined as the main outcome of interest. Therefore, it was reassuring that the subanalysis on DDD led to similar results.

Although the distribution of SEP indicators and prescription fillings were not entirely identical in twins and the population-based sample, the associations between SEP and prescription fillings were indeed, which supports generalisability to the general population in line with previous studies that show that health and mortality in twins are similar to the background population. 5556 Furthermore, the fact that the analysis based only on discordant twin pairs show marginal results similar to those based on the total twin sample was reassuring.

\section{Conclusion and perspectives}

In this study, based on a comprehensive twin cohort, we observed a social inequality in fillings of prescription medicine, showing fewer prescription fillings among people with high SEP. This association attenuated within twin pairs for most types of prescription fillings, except those targeting the nervous system. The attenuation was most pronounced in MZ twins. Measurement error can contribute to the observed attenuation of association, but it is likely to account only for a minor fraction, 
considering the exposure and outcome measures in this study. As for potential non-shared confounding we would, if anything, expect it to bias the estimates away from the null.

We therefore interpret the findings as an indication that at least a part of the observed social inequality in prescription fillings is explained by shared familial factors. The implications of these findings are by no means a disqualification of SEP as a determinant of health, but rather an indication that family matters in the production of social health inequalities; most likely through early environment, and possibly also genetic factors. Recognising biological components and early life exposures as important explanatory factors may improve our understanding of the multifaceted aetiology of health inequalities over the life course and increase the potential for effective and targeted interventions.

\author{
Author affiliations \\ ${ }^{1}$ Unit of Epidemiology, University of Southern Denmark, Odense, Denmark \\ ${ }^{2}$ Danish Aging Research Center, Odense, Denmark \\ ${ }^{3}$ Section of Biostatistics, University of Copenhagen, Copenhagen, Denmark \\ ${ }^{4}$ Unit of Biostatistics, University of Southern Denmark, Odense, Denmark \\ ${ }^{5}$ Section of Social Medicine, University of Copenhagen, Copenhagen, Denmark \\ ${ }^{6}$ Glostrup University Hospital, Research Center for Prevention and Health, \\ Glostrup, Denmark
}

Contributors $\mathrm{KC}$ and $\mathrm{MO}$ formulated the original study idea and provided funding. MM, KC, MO and A-MNA further developed the study idea and design of the study. MM carried out the data analyses in collaboration with PKA and MG. All authors participated in interpretation and discussion of the findings. MM drafted the first version of the manuscript, but all authors have contributed to the revisions and have approved the final version of the paper.

Funding This work is supported by a grant from the VELUX Foundation (95-103-11419), a grant from the Danish Cancer Society (SU08001) and from the Danish Council for Independent Research (social sciences, 09-06008). The funding bodies had no influence on the contents of this paper.

Competing interests None.

Ethics approval The Danish Data Protection Board (2000-54-0047).

Provenance and peer review Not commissioned; externally peer reviewed.

Data sharing statement No additional data are available.

Open Access This is an Open Access article distributed in accordance with the Creative Commons Attribution Non Commercial (CC BY-NC 3.0) license, which permits others to distribute, remix, adapt, build upon this work noncommercially, and license their derivative works on different terms, provided the original work is properly cited and the use is non-commercial. See: http:// creativecommons.org/licenses/by-nc/3.0/

\section{REFERENCES}

1. Mackenbach JP, Stirbu I, Roskam AJ, et al. Socioeconomic inequalities in health in 22 European countries. $N$ Engl J Med 2008;358:2468-81.

2. Adler NE, Ostrove JM. Socioeconomic status and health: what we know and what we don't. Ann N Y Acad Sci 1999;896:3-15.

3. Davey SG, Hart C, Hole D, et al. Education and occupational social class: which is the more important indicator of mortality risk? $J$ Epidemiol Community Health 1998;52:153-60.

4. Marmot M, Ryff CD, Bumpass LL, et al. Social inequalities in health: next questions and converging evidence. Soc Sci Med 1997:44:901-10.

5. Ekholm O, Kjøller M, Davidsen M, et al. Sundhed og Sygelighed $i$ Danmark \& udviklingen siden 1987 [Danish Health and Morbidity survey and trends since 1987]. Copenhagen: National Institute of Public Health, 2006.
6. Gundgaard J. Income related inequality in prescription drugs in Denmark. Pharmacoepidemiol Drug Saf 2005;14:307-17.

7. Danish Medicines Agency. Total sales of medicines in Denmark, 2008-2012. 2013

8. Weitoft GR, Rosen M, Ericsson O, et al. Education and drug use in Sweden-a nationwide register-based study. Pharmacoepidemiol Drug Saf 2008;17:1020-8.

9. Nielsen MW, Hansen EH, Rasmussen NK. Prescription and non-prescription medicine use in Denmark: association with socio-economic position. Eur J Clin Pharmacol 2003;59:677-84.

10. Lu CY, Barratt J, Vitry A, et al. Charlson and Rx-risk comorbidity indices were predictive of mortality in the Australian health care setting. J Clin Epidemiol 2011;64:223-8.

11. Rosholm JU, Christensen K. Relationship between drug use and self-reported health in elderly Danes. Eur J Clin Pharmacol 1997;53:179-83.

12. Hershman DL, Simonoff PA, Frishman WH, et al. Drug utilization in the old and how it relates to self-perceived health and all-cause mortality: results from the Bronx Aging Study. J Am Geriatr Soc 1995;43:356-60.

13. Wamala S, Merlo J, Bostrom G, et al. Socioeconomic disadvantage and primary non-adherence with medication in Sweden. Int J Qual Health Care 2007;19:134-40.

14. Wamala S, Merlo J, Bostrom G, et al. Perceived discrimination, socioeconomic disadvantage and refraining from seeking medical treatment in Sweden. J Epidemiol Community Health 2007;61:409-15

15. Furu K, Straume B, Thelle DS. Legal drug use in a general population: association with gender, morbidity, health care utilization and lifestyle characteristics. J Clin Epidemiol 1997;50:341-9.

16. Adler NE, Stewart J. Health disparities across the lifespan: meaning, methods, and mechanisms. Ann N Y Acad Sci 2010;1186:5-23.

17. Lichtenstein P, Harris JR, Pedersen NL, et al. Socioeconomic status and physical health, how are they related? An empirical study based on twins reared apart and twins reared together. Soc Sci Med 1993;36:441-50.

18. Smith GD, Blane D, Bartley M. Explanations for socio-economic differentials in mortality. Evidence from Britain and elsewhere. Eur $J$ Public Health 1994;(4):131-44.

19. Gilman SE, Loucks EB. Invited commentary: does the childhood environment influence the association between every $\mathrm{x}$ and every $\mathrm{y}$ in adulthood? Am J Epidemiol 2012;176:684-8.

20. Mackenbach JP. Genetics and health inequalities: hypotheses and controversies. J Epidemiol Community Health 2005;59:268-73.

21. Madsen M, Andersen AM, Christensen $\mathrm{K}$, et al. Does educational status impact adult mortality in Denmark? A twin approach. $\mathrm{Am} \mathrm{J}$ Epidemiol 2010;172:225-34.

22. Behrman JR, Kohler HP, Jensen VM, et al. Does more schooling reduce hospitalization and delay mortality? New evidence based on Danish twins. Demography 2011;48:1347-75.

23. Madsen M, Andersen PK, Gerster M, et al. Does the association of education with breast cancer replicate within twin pairs? A registerbased study on Danish female twins. Br J Cancer 2011;104:520-3.

24. Osler M, McGue M, Christensen K. Socioeconomic position and twins' health: a life-course analysis of 1266 pairs of middle-aged Danish twins. Int J Epidemiol 2007;36:77-83.

25. Fujiwara T, Kawachi I. Is education causally related to better health? A twin fixed-effect study in the USA. Int $J$ Epidemiol 2009;38:1310-22.

26. Institute For Statistics. ISCED 1997 International Standard Classification of Education. UNESCO, 2006.

27. Organisation for Economic Co-operation and Development The OECD list of social indicators. Organisation for Economic Co-operation and Development, 1982.

28. Guidelines for ATC classification and DDD assignment. 13th edn. Oslo: WHO Collaboration Centre for Drug Statistics Methodology, 2010.

29. Skytthe A, Kyvik K, Holm NV, et al. The Danish Twin Registry: 127 birth cohorts of twins. Twin Res 2002;5:352-7.

30. Christiansen L, Frederiksen H, Schousboe K, et al. Age- and sex-differences in the validity of questionnaire-based zygosity in twins. Twin Res 2003;6:275-8.

31. Cook RJ, Lawless JF. Methods based on counts and rate functions. The statistical analysis of recurrent events. New York: Springer, 2007.

32. Lin DY. Linear regression analysis of censored medical costs. Biostatistics 2000;1:35-47.

33. Frisell T, Oberg S, Kuja-Halkola R, et al. Sibling comparison designs: bias from non-shared confounders and measurement error. Epidemiology 2012;23:713-20.

34. Kaufman JS, Glymour MM. Splitting the differences: problems in using twin controls to study the effects of BMI on mortality. Epidemiology 2011;22:104-6. 
35. Frisell $\mathrm{T}$, Pawitan $\mathrm{Y}$, Langstrom $\mathrm{N}$. Is the association between general cognitive ability and violent crime caused by family-level confounders? PLoS ONE 2012;7:e41783.

36. Carlsson S, Andersson T, de FU, et al. Body mass index and mortality: is the association explained by genetic factors? Epidemiology 2011;22:98-103.

37. Nielsen MW, Gundgaard J, Hansen EH, et al. Use of six main drug therapeutic groups across educational groups: self-reported survey and prescription records. J Clin Pharm Ther 2005;30: 259-69.

38. van Doorslaer E, Masseria C, Koolman X. Inequalities in access to medical care by income in developed countries. CMAJ 2006;174:177-83.

39. Horwitz AV, Videon TM, Schmitz MF, et al. Rethinking twins and environments: possible social sources for assumed genetic influences in twin research. J Health Soc Behav 2003;44:111-29.

40. Mitchell KS, Mazzeo SE, Bulik CM, et al. An investigation of a measure of twins' equal environments. Twin Res Hum Genet 2007;10:840-7.

41. Kuh D, Ben-Shlomo Y, Susser E. A life course approach to chronic disease epidemiology. 2nd edn. New York: Oxford University Press, 2004.

42. Galobardes B, Lynch JW, Smith GD. Is the association between childhood socioeconomic circumstances and cause-specific mortality established? Update of a systematic review. J Epidemiol Community Health 2008;62:387-90.

43. Lundborg $P$. The health returns to education: what can we learn from twins? IZA Discuss Paper 2008(3399):1-32.

44. Lundborg P, Lyttkens $\mathrm{CH}$, Nystedt P. Human capital and longevity. Evidence from 70,000 MZ and DZ twins. Sweden: Lund University, 2011.

45. Sondergaard G, Mortensen LH, Nybo Andersen AM, et al. Does shared family background influence the impact of educational differences on early mortality? Am J Epidemiol 2012;176:675-83.
46. Naess O, Hoff DA, Lawlor D, et al. Education and adult cause-specific mortality-examining the impact of family factors shared by 871367 Norwegian siblings. Int J Epidemiol 2012;41:1683-91.

47. Osler M, Madsen M, Nybo Andersen AM, et al. Do childhood and adult socioeconomic circumstances influence health and physical function in middle-age? Soc Sci Med 2009;68:1425-31.

48. Mortensen LH. Socioeconomic inequality in birth weight and gestational age in Denmark 1996-2007: using a family-based approach to explore alternative explanations. Soc Sci Med 2013;76:1-7.

49. Lawlor DA, Clark H, Davey SG, et al. Childhood intelligence, educational attainment and adult body mass index: findings from a prospective cohort and within sibling-pairs analysis. Int $J$ Obes (Lond) 2006;30:1758-65.

50. Gilman SE, Martin LT, Abrams DB, et al. Educational attainment and cigarette smoking: a causal association? Int J Epidemiol 2008;37:615-24.

51. Amin V, Behrman JR, Spector TD. Does more schooling improve health outcomes and health related behaviors? Evidence from U.K. twins. Economics of Education Review 2013;35:134-48.

52. Webbink D, Martin NG, Visscher PM. Does education reduce the probability of being overweight? J Health Econ 2010;29:29-38.

53. Krieger N, Chen JT, Coull BA, et al. Lifetime socioeconomic position and twins' health: an analysis of 308 pairs of United States women twins. PLoS Med 2005;2:e162.

54. Sondergaard G, Mortensen LH, Andersen AM, et al. Social inequality in breast, lung and colorectal cancers: a sibling approach. BMJ Open 2013;3:pii:e002114

55. Christensen K, Wienke A, Skytthe A, et al. Cardiovascular mortality in twins and the fetal origins hypothesis. Twin Res 2001;4:344-9.

56. Christensen K, Vaupel JW, Holm NV, et al. Mortality among twins after age 6: fetal origins hypothesis versus twin method. BMJ 1995;310:432-6. 